\title{
Instructional quality of mathematics teaching and mathematics teacher education
}

\author{
Salvador Llinares ${ }^{1}$
}

Published online: 29 January 2021

(c) The Author(s), under exclusive licence to Springer Nature B.V. part of Springer Nature 2021

The four articles in this issue have the instructional quality as a shared idea, although they differ on different levels of attention. These contributions display some facets of how the construct "instructional quality" is tackled in the mathematics education field, and particularly, in mathematics teacher education as a discipline. These facets are as follows: how instructional quality may be conceptualized and measured when classroom observation protocols are designed; the relationships between mathematical knowledge for teaching and the instructional quality; the relationship between credentials to enter a selective alternative route programs and the instructional quality of graduates; and how prospective mathematics teachers learn to identify and develop teaching strategies and practices for supporting the mathematical instruction of quality.

Although being an effective teacher has a situated meaning in time and the curricular context, the quality of mathematical instruction is usually considered in relation to the students' outcomes. For example, changes in curriculum standards and what students are expected to learn increase teachers' demands and determine how effective teaching is understood in each moment. However, understanding the relationship between students' outcomes and mathematics teaching is a complex task due to the difficulties of its conceptualization and the identification of the factors that articulates it. For example, some factors usually linked to instructional quality are teacher knowledge, lesson design, the nature of the interactions in the lesson (e.g., enacted mathematics knowledge for teaching and learning and how to respond to children's ideas), and how the subject matter is made available to students (the cognitive demand of the tasks). However, to further understand the instructional quality of mathematics teaching it is also necessary to consider contextual factors - such as the availability of curriculum material or adequate support, and the teachers' epistemological positions.

From the mathematics teacher education perspective, understanding the relationships between teacher knowledge and the instructional quality can provide information for the design of teacher preparation programs (initial, induction and alternative route programs). This situation generates goals in teacher education programs focused on how prospective teachers can recognize and enact effective teaching practices for supporting students' learning. The papers of this issue present four snapshots of different perspectives on the

Salvador Llinares

sllinares@ua.es

1 Universidad de Alicante, Alicante, Spain 
relationships between the instructional quality of mathematics teaching and mathematics teacher education.

Bostic and colleagues perform a review of classroom observation protocols used to measure instructional quality in mathematics education. This review is addressed to characterize "methods of capturing, analyzing, and understanding the events that unfold in mathematics classrooms." The specific focus is to provide information about how "quality" teaching is operationalized in the observation tools and how the bias from the protocols used to observe is made explicit. A relevant aspect of this article is the focus on how classroom observations are used as research data-linked to the purpose of classroom observation-and how evidence-based validity arguments are elicited. Indeed, the use of classroom observation protocol and the validity arguments supporting their use can be similar or different, influencing the outcomes related to the instructional quality.

Santagata and Lee examine the association between mathematical knowledge for teaching and instructional quality in first-year elementary school teachers (novice teachers). The aim is to understand how novice teachers draw on their knowledge to inform about instructional decisions. Through three case studies of elementary school teachers, authors illustrate how teachers use their knowledge to create learning opportunities for students and show different associations between teacher knowledge and instructional quality. This study reports different associations between teacher knowledge (measured with a mathematical knowledge for teaching, MKT, questionnaire completed by the teachers) and instructional quality from a classroom observation protocol (mathematical quality of instruction, MQI). The differences among these associations raise the question about what factors might impact instructional quality. From these three case studies, authors highlight the role of lesson design, mathematics tasks and participation structures on instruction to explain the relationships between teacher knowledge and instructional quality. The case studies are used to generate possible explanations of the differences in the relationships between the facets of mathematical knowledge for teaching and the different dimensions of instructional quality.

The papers of Santagata and Lee, and Bostic and his colleagues focus our attention on the difficulty of examining the relationships between mathematics teacher knowledge and the instructional quality. These relationships require that researchers are explicit and transparent in their methodological choices and provide evidence-based validity arguments.

Cooley and colleagues' article uses the theory of credentialism ("the educational credentials allow privileged groups to control access to desirable professions and justify their power as meritocratic") to indicate that the credentials from selective alternative route programs do not allow to assume that teachers may enact a mathematics teaching of quality. Through two case studies (with data collected during 10 years, from 2006/7 to 2016) contextualized in New York City, Cooley and colleagues identify gaps in the assumption that assume the relation between hold determinate math credentials (e.g., calculus credential) and being an effective mathematics teacher. This article shows that there is little or no connection between the credentials' use value, the actual knowledge and skills attained through the credentialing process. In Cooley and colleagues' words, "the credential is the cultural currency, not the knowledge or competence it supposedly represents." In this study, the instructional quality of mathematics teaching from classroom observation was measured using individual lessons as the unit of analysis (with the dimensions: instructional style, methods of explaining content and student-teacher interactions), and the tasks' mathematical demand as the subunit.

Warshauer and colleagues analyze the development of prospective teachers' perspectives on teaching practices and strategies that may support students' productive struggle 
in learning mathematics - a nuance of mathematics teaching of quality. They focus on changes in how prospective teachers recognize teaching practices that support students making sense to mathematics content-productive struggle. Warshauer and colleagues provide prospective teachers with two frameworks, productive struggle framework and noticing framework, that support them in noticing students' productive struggle and in identifying useful teaching practices to support this struggle. The productive struggle framework, PSF, provides prospective teachers with structured opportunities to recognize specific teaching practices that support students' productive struggle when they analyze videotaped lessons. Noticing framework, NF, helps prospective teacher to attend to and interpret relevant mathematics aspects in the students' mathematics struggle in the tasks, and to recognize the teacher's decision in the teaching practice enacted. Connecting these two frameworks, Warshauer and colleagues investigate how prospective teachers link their mathematics content knowledge to their noticing of students' mathematical activity and the teacher's response.

In the four articles in this issue, instructional quality of mathematics teaching is considered. However, each paper adopts a different perspective. One of the studies focuses on the design of classroom observation protocols and how to conceptualize the construct "instructional quality" and its measurement (as in the Bostic and his colleagues' article). Other studies focus on possible factors influencing the mathematical quality of instruction, such as the teacher's knowledge, in the context of novice teachers (Santagata and colleagues' article) or how prospective teachers learn to recognize nuances of students' struggle with a mathematical task and characteristics of different teaching practices enacted in teacher's response (Warshauer and colleagues' article). However, other scholars question the assumption on the relationship between having certain credentials and the skills and knowledge to enact mathematical instruction of quality (Cooley and colleagues' article). Therefore, the studies of this issue can be considered different snapshots of how the reflection on the instructional quality of mathematics teaching can interact with mathematics teacher education. Furthermore, these papers show the complexity of this field. In this way, we can understand the studies of this issue as instances of how researchers open the door to the communication between mathematics teacher education and the instructional quality of mathematics teaching.

Publisher's Note Springer Nature remains neutral with regard to jurisdictional claims in published maps and institutional affiliations. 